\section{DOUBLING UP}

A review of agency documents for 22 grant pairs flagged up by an automated search for duplicated text suggested that about half warranted closer scrutiny.

3 GRANTS MAY NOT HAVE BEEN DECLARED TO BOTH AGENCIES

BOTH GRANTS DECLARED, BUT NOT IN A TIMELY WAY

5 BOTH GRANTS DECLARED, BUT OVERLAP NOT ADJUSTED FOR

4 OVERLAP IDENTIFIED AND RESOLVED

4 NO OVERLAP EXISTED

4 INSUFFICIENT INFORMATION TO ASSESS

University of Illinois at Urbana-Champaign. "It's a morass," she says.

That leaves plenty of room for confusion. For example, when medical researcher Allen Gao of the University of California, Davis, won an army grant to study androgen-receptor signalling in prostate cancer, officials there worked with him to change his goals so that his application would not overlap with an NIH grant that he had been awarded in 2001. But when Gao disclosed the army grant to the NIH in a 2002 progress report, the agency's officials began what they termed "extensive discussions" with Gao. They concluded that his two grants still overlapped, and reduced the NIH grant by $\$ 75,000$. "I believed that the issue had been resolved," says Gao.

Researchers say that they are eager for clarity about the limits of acceptable behaviour when chasing funding. The NIH explains that it is acceptable for researchers to submit similar requests to different agencies without disclosing other grants, because this information is required only at what is called the 'just-in-time' stage, before an award is finalized.

Some researchers already follow that principle. In one case identified by Garner's search, Michael Zuscik, a medical researcher at the University of Rochester in New York, submitted identical proposals to the army and the $\mathrm{NIH}$. But adjustments he made to the NIH proposal in response to a reviewer's scientific critique removed overlap with the army grant, he says. "This approach to securing support for research is a common method - submit the aims to more than one appropriate funding agency in the hope one will 'hit."'

Zuscik used the army money to test the effect of nicotine on fracture-healing in mice, and the NIH funds to test the effect of cigarette smoke on the same process - different science that nevertheless required some of the same control experiments. Zuscik says that the repetition was required to ensure scientific rigour. Although grant files show that Zuscik alerted the NIH to the army grant, the army has told Nature that it had not been aware of the NIH funding, and is now researching both awards to see whether they overlap.
Michael Emch, a geographer at the University of North Carolina at Chapel Hill, argues that there will always be at least some intellectual overlap between different projects run by the same researcher. Two of his grants were picked out by Garner's search because they had the same title and similar abstracts. A review of the full grant applications shows that the hypotheses and much of the text describing their methodologies is also identical. But Emch says that he did not charge both agencies for the same expenses, such as labour and lab equipment. Emch has an extremely broad research programme, and the NIH money was used to apply general medical-geography methods that had been developed with funds from the NSF to study cholera, he says.

Gunsalus points out that such grants may overlap for practical, as well as intellectual, reasons. Researchers who have large projects may carve out different lines of inquiry within them but submit similar grant applications for each one; or they might use seed funding from one agency to start a project, then try to raise additional funds from another.

Garner insists that agencies need more-consistent regulations and definitions of overlap. $\mathrm{He}$ also advocates for a central grant database that flags duplicated text automatically - although a manual review would still be required to pin down whether overlap exists. "The average grant is about $\$ 450,000$. A couple of days of labour to avoid overlap should be worth that," he says. -

\title{
Magnetic logic makes for mutable chips
}

\section{Alternative transistor relies on exotic semiconductor.}

\section{BY GEOFF BRUMFIEL}

$\mathrm{S}$ oftware can transform a computer from a word processor to a number cruncher to a video telephone. But the underlying hardware is unchanged. Now, a type of transistor that can be switched with magnetism instead of electricity could make circuitry malleable too, leading to more efficient and reliable gadgets, from smart phones to satellites.

Transistors, the simple switches at the heart of all modern electronics, generally use a tiny voltage to toggle between 'on' and 'off'. The voltage approach is highly reliable and easy to miniaturize, but has its disadvantages. First, keeping the voltage on requires power, which drives up the energy consumption of the microchip. Second, transistors must be hardwired into the chips and can't be reconfigured, which means computers need dedicated circuitry for all their functions.

A research group based at the Korea Institute of Science and Technology (KIST) in Seoul, South Korea, has developed a circuit that may get around these problems. The device, described in a paper published on Nature's website on 30 January, uses magnetism to control the flow of electrons across a minuscule bridge of the semiconducting material indium antimonide (S. Joo et al. Nature http://dx.doi. org/10.1038/nature11817; 2013). It is "a new and interesting twist on how to implement a logic gate", says Gian Salis, a physicist at IBM's Zurich Research Laboratory in Switzerland.

\section{MAGNETIC LOCK}

In a circuit made of the semiconductor indium antimonide, a magnetic field can lift electrons over positively charged holes, switching the device on - or deflect them into the holes, turning it off.

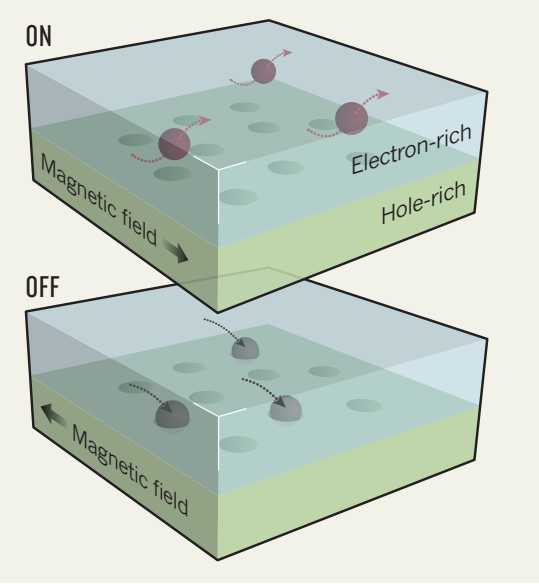

The bridge has two layers: a lower deck with an excess of positively charged holes and an upper deck filled predominantly with negatively charged electrons. Thanks to the unusual electronic properties of the indium antimonide, the researchers can control the flow of electrons across the bridge using a 
- perpendicular magnetic field. When they set the field in one direction, electrons are steered away from the positive bottom deck and flow freely. When the magnetic field is flipped, the electrons crash into the lower deck and recombine with the holes - effectively turning the switch off (see 'Magnetic lock').

The ability of a magnetic logic gate to hold the switch on or off without a voltage "could lead to great reduction of energy consumption", says study co-author Jin Dong Song, a physicist at KIST. Even more impressively, the magnetic switches "can be handled like software", he says, by simply flipping the field to enable or disable a circuit. Thus a mobile phone could, for example, reprogram a bit of its microcircuitry to process video while its user watched a clip on YouTube, then switch the chip back to signal processing to take a phone call. This could greatly reduce the volume of circuitry needed inside the phone.

Such reconfigurable logic could be invaluable in satellites, adds Mark Johnson of the Naval Research Laboratory in Washington DC, a co-author of the paper. If part of a chip failed in orbit, another sector could simply be reprogrammed to take over. "You've healed the circuit and you've done it from Earth," he says.

To really catch on, however, the magnetic logic would have to be integrated with existing silicon-based technologies. That may not be easy. For one thing, indium antimonide, the semiconductor crucial to the circuits, doesn't lend itself well to manufacturing processes used to make modern electronics, according to Junichi Murota, a researcher working with nanoelectronics at Tohoku University in Japan. But Johnson says that it may eventually be possible to build similar bridges with silicon.

Integrating the miniature magnets needed to control the devices into a normal chip wouldn't be easy either. Companies should be able to solve these challenges, but only if they decide the devices are worthwhile, says Salis. At the moment, he adds, it is not clear whether the devices will perform well at the sizes needed for a practical chip - much smaller than the micrometre dimensions of the prototypes.

But Johnson notes that magnetism is already catching on in circuit design: some advanced devices are beginning to use a magnetic version of random access memory, a type of memory that has historically been built only with conventional transistors. "I think a shift is already under way," he says. .

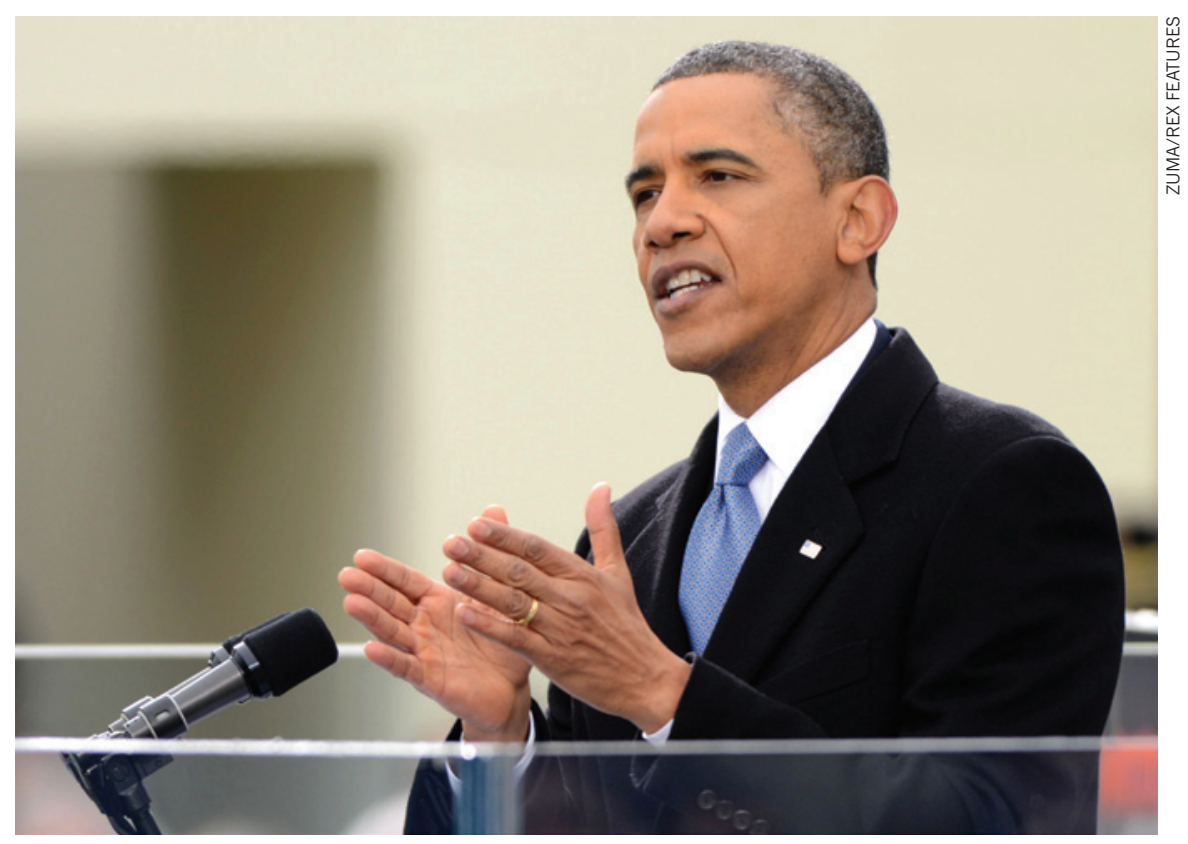

US President Barack Obama reinforced environment promises in his second inaugural address.

ENVIRONMENT

\section{Obama rekindles climate hopes}

\section{President will use regulations to sidestep stalled Congress.}

\section{BY JEFF TOLLEFSON}

卫 Throughout his re-election campaign, US President Barack Obama rarely said the words 'climate change'. But in his second inaugural address, on 21 January, Obama renewed a commitment to address global warming, citing both moral and economic imperatives. To fail, he said, "would betray our children and future generations".

The 2010 demise of a climate bill that would have enacted a cap-and-trade system to limit greenhouse-gas emissions remains one of the key failures of Obama's first term. With a divided Congress still standing in the way of legislation, the administration is likely to rely on its own power to impose new regulations, once Obama has replaced the retiring heads of three agencies key to the climate agenda (see 'Climate team change').

As proof of what is possible, Obama can point to a welcome, if unexpected, reduction in US greenhouse-gas emissions during his first term. The decline is in part a result of the economic slowdown and a shift in electricity production from coal to natural gas, which has become cheap and plentiful in recent years. But policies have helped. These include federal greenhouse-gas standards for vehicles, and the introduction by more than half of the states of significant energy and climate initiatives that could deliver further

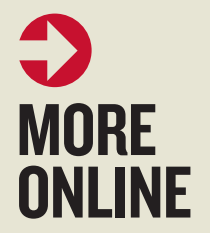

\section{TOP STORY}

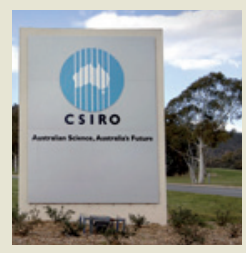

Australian research agency raises ongoing questions on alleged bullying go.nature.com/squzlk

\section{MORE NEWS}

- Small oil spills may actually be bigger than originally thought go,nature. com/a64awg

- Ageing causes poor sleep and impairs memory go.nature.com/hppcay - Aphrodisiac craze endangers Himalayan caterpillar go.nature.com/yegirz

\section{SLIDESHOW}

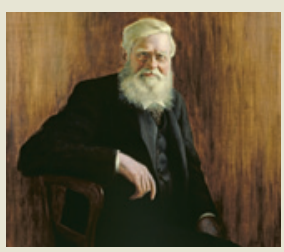

Letters of Alfred Russel Wallace go online go.nature.com/ jepahh 